\title{
Muster: Verlängerung einer sachgrundlosen Befristung
}

\section{Vereinbarung zur Verlängerung der Befristung}

zwischen

- Arbeitgeber -

und

- Arbeitnehmer -

besteht ein sachgrundlos befristeter Arbeitsvertrag vom

Hiermit wird die Befristung verlängert bis zum Ablauf des

Im Übrigen gelten die Vereinbarungen des vorgenannten Arbeitsvertrages unverändert fort. Beide Parteien bestätigen mit ihrer Unterschrift, eine Ausfertigung dieses Vertrages erhalten zu haben.

, den

Ort

Arbeitgeber
Datum

Arbeitnehmer 